\title{
Reconstruindo a
}

tecnoliteracia:

uma abordagem de

múltiplas literacias ${ }^{1}$

\author{
Douglas Kellner \\ Professor catedrático na Escola de Pós-Graduação em Estudos de Educação e Informação na \\ Universidade da Califórnia (UCLA), Los Angeles. \\ E-mail: kellner@ucla.edu
}

Richard Kahn

PHD pela Escola de Pós-Graduação em Estudos de Educação e Informação na Universidade da Califórnia (UCLA), Los Angeles.

E-mail:rvkahn@ucla.edu

Resumo: Muito tem sido escrito sobre o conceito de literacia tecnológica. Este artigo começa com uma breve análise dos significados que "tecnologia" e "literacia" receberam, no sentido de procurar entender a qual tipo de conhecimento e habilidades a "tecnoliteracia" se refere. Richard Kahn e Douglas Kellner resumem as amplas trajetórias de desenvolvimento em programas hegemônicos de tecnoliteracias contemporâneas, desde suas supostas origens como "literacia computacional". Em contrapartida, revelam como essa abordagem tem sido tacitamente desafiada em nível institucional global por meio do Projeto 2000+ das Nações Unidas, e teorizam como isso pode estar ligado a um projeto democrático de revisão da educação por meio das múltiplas literacias. Por fim, os autores refletem sobre o que significará reconstruir amplamente a tecnoliteracia nas diversas áreas da sociedade.

Palavras-chave: tecnologia; literacia; literacia tecnológica; tecnoliteracias; literacia computacional.
Abstract: Much has been written that describes the history of the concept of "technological literacy". This paper begins with a brief examination of the meanings that "technology" and "literacy" have received towards achieving insight into what sort of knowledge and skills "technoliteracy" hails. Richard Kahn and Douglas Kellner then summarize the broad trajectories of development in hegemonic programs of contemporary technoliteracy from their arguable origins as "computer literacy". In contradistinction, they reveal how this approach has been tacitly challenged at the global institutional level through the United Nations' Project 2000+, and theorize how this might link up with a democratic project of re-visioning education though multiple literacies. Finally, in closing, Kahn and Kellner think about what it will mean to reconstruct "technoliteracy" broadly in the various areas of society.

Keywords: technology; literacy; technological literacy; technoliteracies; computational literacy. 
2 DEWEY, J. Democracy and Education: An Introduction to the Philosophy of Education. Carbondale and Edwardsville: Southern Illinois University Press, 1916

3 MCLUHAN, M. Understanding Media: The Extensions of Man. Nova York: Signet Books, 1964.

4 WELLS, H. G. World Brain. Nova York: Doubleday, 1938

5 Sobre o conceito de "espetáculo midiático", ver Kellner (2005, 2003a).

Baseia-se na noção de Guy Debord de "sociedade do espetáculo", que descreve uma sociedade midiática e de consumo organizada em torno da produção e do consumo de imagens, mercadorias e eventos encenados. Essa abordagem crítica caracteriza esses fenômenos da cultura midiática que encarnam os valores fundamentais da sociedade contemporânea, e serve para introduzir os indivíduos em seu modo de vida, dramatizando suas controvérsias e lutas, bem como seus modos de resolução de conflitos.

6 CASTELLS, M. The Information Age: Economy, Society and Culture Vol.I: The Rise of the Network Society. Cambridge: Blackwell Publishers, 1996.

7 KELLNER, D. Media Spectacle. Londres/Nova York: Routledge, 2003a, pp. 11-15.

8 A ideia de que diferentes formas de conhecimento (por exemplo, diferentes tipos de perguntas que por sua vez geram respostas diferentes) são produzidas enquanto um grupo oprimido começa a atingir uma identidade coletiva face a face com as questões sociais, culturais e políticas do dia é uma
O grande avanço da ciência elétrica na última geração está associado, como causa e efeito, à aplicação de agentes elétricos nos meios de comunicação, transporte, iluminação de cidades

e de casas e em outros bens econômicos de produção. Além disso, estes fins são sociais, e o fato de se acharem intimamente associados à noção de lucros privados não é devido a alguma coisa que lhes seja peculiar, e, sim, por terem sido desviados para o uso particulares: circunstância que investe a escola da responsabilidade de restabelecer-lhes a conexão, no espírito das próximas gerações, com os interesses científicos e sociais do povo².

\section{INTRODUÇÃO}

O debate atual sobre a natureza e os benefícios da tecnoliteracia é hoje, sem dúvida, um dos temas mais acaloradamente disputados. Juntamente com as suas análises e recomendações relacionados, nas últimas três décadas tem-se visto uma variedade de stakeholders públicos e corporativos, grupos acadêmicos, organizações de interesses culturais e sociais globais/locais competindo pela definição do termo "literacia tecnológica". Enquanto noções utópicas como a "aldeia global", de Marshall McLuhan ${ }^{3}$, e o "cérebro mundial", de H. G. Wells ${ }^{4}$, imaginam um mundo tecnológico de crescente unidade na diversidade, nossa perspectiva é talvez melhor caracterizada como uma cultura global do espetáculo midiático complexa e sociopoliticamente estratificada ${ }^{5}$ e como megatécnicas de informação mundial em contínuo crescimento ${ }^{6}$, rumo à sociedade tecnocapitalista do infotenimento ${ }^{7}$. Como tal, há pouca razão para se esperar uma concordância geral em relação a que tipos de conhecimentos são decorrentes da tecnoliteracia, que tipos de práticas podem desenvolvê-la de maneira mais eficiente ou mesmo a respeito de que formações institucionais a tecnoliteracia pode melhor servir e ser servida. Além disso, apesar de existirem muitos pontos de vista divergentes e conflitantes sobre tecnoliteracia, só recentemente esses debates começaram a ser desafiados por movimentos de oposição baseados em raça, classe, gênero, anti-imperialismo e no bem-estar ecológico. Como esses diversos movimentos começam a fazer suas próprias perguntas sobre a articulação cada vez mais crescente entre tecnologia, educação, a construção de uma cultura globalizada, a esfera política e a economia, podemos ver claramente que a tecnoliteracia tornou-se de uma vez múltipla em tomar diferentes formas em diferentes países e culturas, ao mesmo tempo em que se torna cada vez mais importante para as pessoas em todo o mundo ${ }^{8}$.

Muito tem sido escrito sobre a descrição histórica do conceito de literacia tecnológica (Petrina; Selfe; Jenkins; Waetjen; Lewis e Gagel; Dyrenfurth; Todd; Hayden) e, como percebido, uma literatura que trata sobre as tecnoliteracias emancipatórias começou a surgir na última década (Hammer e Kellner; Kellner; Lankshear e Snyder; Petrina; Luke; Bromley e Apple). 
Não procuramos reinventar a roda ou reproduzir o mais do mesmo. Mas, considerando que existe uma grande variedade publicada de definições sobre tecnoliteracia, torna-se frutífero começar com um breve exame dos significados que "tecnologia" e "literacia" têm recebido a fim de alcançar com maior precisão exatamente que tipo de conhecimento e de habilidades a tecnoliteracia abrange.

Então, vamos inicialmente sintetizar as amplas trajetórias hegemônicas do trabalho nas formas de tecnoliteracias patrocinadas pelos Estados Unidos. Assim, nós as examinamos a partir de suas origens políticas duvidosas, como a "literacia computacional", descrita pelo relatório A Nation at Risk de 1983 com apelos pela integração da tecnologia no currículo e as abordagens-padrão do ato No Child Left Behind de 2001 e do U.S. National Educational Technology Plan.

Continuamos com a análise do contínuo impulso no currículo da administração de Obama em todos os níveis para o suporte em Ciências, Tecnologia, Engenharia e Gerenciamento de literacias (STEM) ${ }^{9}$, bem como a sua afirmação recentemente promovida sobre a necessidade de todos os alunos terem "competências do século XXI" como parte de parâmetros curriculares nacionais ${ }^{10}$.

Concordando com Petrina ${ }^{11}$ sobre tal desenvolvimento ser em grande parte a construção de uma versão neutralizada de tecnoliteracia que reforça uma política conservadora de "supremacia competitiva" ideológica: nota-se que ela foi tacitamente defendida na esfera institucional global com o Projeto 200+ das Nações Unidas.

No entanto, enquanto elementos desse programa permanecem eficazes, transformações mais recentes em nível global mostram que a ideia de tecnoliteracia para o desenvolvimento sustentável passou a ser contestada e começou a servir ideologias funcionais em nações tecnologicamente menos desenvolvidas e pensadas no sentido de torná-las mais economicamente competitivas globalmente.

Na segunda metade desse artigo, nós analisamos como a contestação de formas hegemônicas de tecnoliteracia pode estar ligada a um projeto democrático de oposição para a reforma da educação por meio de múltiplas literacias. Por fim, discutimos o que significará reconstruir as tecnoliteracias e propomos que o maior objetivo será envolver pessoas em movimentos de larga escala para a transformação ativa de pensamentos, políticas e práticas de tecnoliteracia dominantes por meio da politização de normas e pensamentos hegemônicos da tecnologia que frequentemente impregnam terrenos diversos da sociedade.

\section{TECNOLOGIA, LITERACIA, TECNOLITERACIA: DEFINIÇÕES}

Literacia tecnológica é um termo de pouco significado e muitos $\operatorname{significados}^{12}$.

Após a primeira consideração, procurar uma definição adequada de "tecnologia” parece ser algo extremamente técnico. Certamente, nas discussões sobre tecnologia, é raro as pessoas precisarem de esclarecimento do termo. Num dado contexto, se é sugerido que a tecnologia está causando problemas visão central da teoria crítica conhecida como teoria da perspectiva feminista (Harding, 2004). Pode-se argumentar que essa ideia está na teoria crítica em geral, e uma formulação radical pode ser vista em Marcuse (1965), bem como nas obras de Marx e Engels, como Sandra Harding aponta adequadamente. Mais recentemente, Jeff Share (2008) baseia-se nessa noção de ponto de vista de maneira parecida em sua discussão sobre a literacia midiática crítica.

9 WHITE House, The Educate to Innovate. 2013. Disponível em: $<$ www.whitehouse.gov/ issues/education/k-12/ educate-innovate>.

10 WILSON, J. Three Key Players for $21^{\text {st }}$ Century Skills, John Wilson Unleashed. 2012 Disponível em: <http:// blogs.edweek.org/ed week/john_wilson_un leashed/2012/04/three key_players_for_21st century_skills.html>.

11 PETRINA, S. The Politics of Technological Literacy. International Journal of Technology and Design Education, v. 10, n. 2, 2000, pp. 181-206.

12 TODD, R. D. The Natures and Challenges of Technological Literacy. In: DYRENFURTH, M J.; KOZAK, M. R. (ed.). Technological Literacy. Peoria, IL: Glencoe, McGraw-Hill, 1991. 
ou os aliviando, as pessoas geralmente sabem que tipo de coisa está prestes a culpar ou louvar.

No entanto, o significado popular de "tecnologia" é problematicamente insuficiente em pelo menos dois aspectos. Primeiro, ele equivale a artefatos tecnológicos high tech, tais como máquinas científicas usadas em medicina e biotecnologia, aparatos industriais modernos e componentes digitais como computadores, TICs e outras mídias eletrônicas. Essa visão reducionista falha em reconhecer, por exemplo, que os artefatos indígenas são por si só tecnologias em seu próprio direito, da mesma forma que outros objetos culturais que possam um dia ter representado a vanguarda tecnológica das invenções durante eras históricas anteriores, tais como livros, ferramentas manuais ou mesmo roupas. Em segundo lugar, as concepções populares de tecnologia hoje cometem outro erro: o de interpretar a tecnologia como algo meramente orientado a objetos, identificando-a apenas como tipos de produtos que surgem por meio da indústria. Na verdade, desde o início, a tecnologia sempre significou muito mais; e isso se reflete nas definições recentes de tecnologia como "uma rede fluida ou rede que combina artefatos, pessoas, organizações, significados e conhecimentos culturais"13 ou aquilo que "compreende todo o sistema de pessoas e de organizações, de conhecimento, de processos e de dispositivos que criam e operam artefatos tecnológicos, bem como os artefatos por si mesmos"14. Essas definições mais amplas de tecnologia são baseadas nas importantes ideias de John Dewey, para quem a tecnologia é fundamental para a humanidade e envolve a investigação humana em sua totalidade ${ }^{15}$. Em sua opinião, a tecnologia faz parte de todos os tipos de experiências criativas e de resolução de problemas. Ela deve se estender para além das ciências mais óbvias, uma vez que engloba não apenas as artes e as humanidades, mas também as profissões e as práticas de nossas vidas cotidianas. Nesse sentido, a tecnologia é inerentemente política e histórica, e, na filosofia de Dewey, ela é fortemente vinculada a noções de democracia e de educação, que são consideradas "tecnologias" que pretendem progresso social e maior liberdade para o futuro.

A visão de Dewey é ingênua, mas é descaradamente otimista e esperançosa

13 WAJCMAN, J. Technofeminism. Malden, MA: Polity Press, 2004, p. 106

14 PEARSON, G.; Young, A. T. Technically Speaking: Why All Americans Need to Know More About Technology. National Academies Press, 2002.

15 HICKMAN, L. Philosophical Tools for Technological Culture. Bloomington: Indiana University Press, 2001.

16 ILLICH, I. Tools for Conviviality. Nova York: Harper and Row, 1973, p. 22. de que é inerente ao ser humano a possibilidade de ser suficientemente educado para compreender os problemas que enfrenta e, dessa forma, poder produzir e implementar experimentalmente uma ampla variedade de tecnologias para a resolução de problemas. Enquanto concordamos plenamente com o espírito de Dewey, também reconhecemos que o momento atual está potencialmente assolado pelo problema sem precedentes das diversas formas de opressão tecnológica. Para esse fim, nós também procuramos destacar as ideias do crítico social radical e teórico da tecnologia Ivan Illich (Kahn, 2004; Kahn e Kellner, 2007). Especificamente, a noção de "ferramentas" de Illich reflete a ampla compreensão humanística de tecnologia tratada até aqui, ao mesmo tempo que, adicionalmente, distingue "dispositivos racionalmente concebidos — sejam eles artefatos ou regras, códigos ou operadores - de outras coisas, como alimentos ou implementos, que em uma determinada cultura não são considerados como 
tema de racionalização"16. Consequentemente, Illich polemiza as "ferramentas para convívio", que são tecnologias conscientemente racionadas para trabalhar dentro dos limites culturais e naturais. Em nossa visão, a tecnologia assim definida será útil para uma tecnoliteracia do século XXI desafiada a atender às demandas de um mundo sustentável e ecumênico.

"Literacia" é outro conceito muitas vezes utilizado por educadores e formuladores de políticas, mas de diversas maneiras e para uma ampla gama de propósitos. Em sua forma inicial, a literacia básica era equiparada à proficiência profissional, com linguagem e números tais quais os indivíduos poderiam utilizar no trabalho e na sociedade. Assim, mesmo no início do século XX, a literacia significava, em grande medida, a capacidade de escrever o próprio nome e decodificar textos impressos populares, enquanto o objetivo adicional de autoexpressão escrita apareceu somente nas décadas seguintes. Street ${ }^{17}$ identifica esses atributos como elementos típicos de um modelo autônomo de literacia que é politicamente conservador na medida em que é essencialmente economicista, individualista e é impulsionado por uma teoria do déficit de aprendizagem. Por outro lado, Street caracteriza modelos ideológicos de literacia como prefigurando noções positivas de empoderamento coletivo, contexto social, de codificação e decodificação de textos impressos e não impressos, bem como um compromisso progressivo para competências orientadas para o pensamento crítico.

Em nossa concepção, a "literacia” não é um conjunto único de competências, mas é algo múltiplo que significa desenvolver habilidades envolvidas na utilização eficaz de formas socialmente construídas de comunicação e de representação. Literar-se exige a realização de competências em práticas e em contextos que são regidos por regras e convenções. Assim, consideramos literacias como sendo socialmente construídas nas práticas educativas e culturais que envolvem vários discursos institucionais e pedagogias. Contra a visão autônoma que postula a literacia como estática, consideramos como algo que está em constante evolução e mudança em resposta às transformações sociais e culturais, bem como aos interesses das elites que controlam as instituições hegemônicas. Além disso, é uma parte crucial do processo de literacia que as pessoas entendam os códigos dominantes como hegemônicos. Assim, a nossa concepção de literacia segue Freire e Macedo, que a consideram algo amarrado às questões de poder. Como os autores observam, a literacia é uma política cultural que "promove mudança democrática e emancipatória"18 e que deve ser interpretada como a capacidade de se envolver em uma variedade de formas de problematização e análises dialéticas de si e da sociedade.

Com base em nossas definições de "tecnologia" e "literacia", deveria ser óbvio que, holisticamente concebido, literacias são por si mesmas tecnologias que constituem processos de metaindagações que servem para facilitar e regular os sistemas tecnológicos. A esse respeito, falar de "tecnoliteracias" pode parecer inerentemente tautológico. Por outro lado, no entanto, isso também ajuda a realçar a natureza construída e potencialmente reconstrutiva das literacias, bem como a natureza educativa, social e política das tecnologias. Além disso, mais
17 STREET, B. Literacy in Theory and Practice. Cambridge, UK: Cambridge University Press, 1984.

18 FREIRE, P.; MACEDO, D. Literacy: Reading the Word and the World. Westport, CT: Bergin \& Garvey, 1987, p. viii. 
19 Mesmo que enfatizemos a especificidade social e cultural das tecnologias, não estamos pedindo a adoção universal de tecnologias de ponta, nem estamos ligando-a essencialmente ao progresso como fases necessárias de desenvolvimento. Por outro lado, nós pedimos cautela contra atitudes tecnofóbicas, pois somos a favor de uma visão dialética da tecnologia e sociedade.

20 JENKINS, E. W. Technological Literacy: Concepts and Constructs. Journal of Technology Studies, v. 23, n. 1, 1997. do que nunca, precisamos de reflexão filosófica sobre os fins e propósitos da educação e sobre o que estamos fazendo e tentando alcançar em nossas práticas e instituições educacionais. Tais reflexões informariam uma tecnoliteracia crítica em seu sentido mais profundo, que vê tanto literacias quanto tecnologias como socialmente construídas, informadas por modos dominantes de poder e de dominação e sujeitas à reconstrução e ao uso em formas contra-hegemônicas democratizantes.

Consequentemente, consideramos que as tecnoliteracias contemporâneas estão envolvidas com a necessidade de compreender e de fazer uso de novas mídias e de tecnologias em proliferação, bem como com a economia política que as direciona, no sentido de promover entendimentos democráticos radicais e transformações de nossos mundos. Em um ambiente atual de processos inexoráveis de globalização e de transformação tecnológica, não podemos defender uma política de mãos limpas e de pureza, na qual as pessoas protegem-se de novas tecnologias e de sua propagação transnacional, como em abordagens protecionistas $^{19}$. Em vez disso, as tecnoliteracias devem ser implantadas e promovidas para permitir intervenções populares nas revoluções econômicas e tecnológicas (muitas vezes antidemocráticas) atualmente em curso, desviando potencialmente essas forças para fins progressistas, tais como a justiça social e o bem-estar ecológico.

Consequentemente, as tecnoliteracias abrangem o computador, a informação, a mídia crítica e as literacias multimídia que atualmente são teorizadas sob o conceito de multiliteracias (Cope e Kalantzis; Luke; Rassool; New London Group). Mas enquanto a teoria das multiliteracias muitas vezes permanece focada em tecnologias digitais, com inclinação implícita para a criação de novas habilidades de trabalho de mídia para a era da internet, procuramos destacar explicitamente a adequação social e cultural das tecnologias e fornecer uma crítica da nova economia midiática como sendo tecnocapitalista (Best e Kellner; Kellner), ainda que reconhecendo suas potencialidades progressistas. Assim, recorremos à linguagem das literacias múltiplas (Lonsdale e McCurry, 2004; Kellner, 2000 e 2004) para disseminar uma teoria crítica das tecnoliteracias, como será exposto mais tarde.

\section{TECNOLITERACIA EM CRISE: DOS ESTADOS UNIDOS ÀS NAÇÕES UNIDAS}

Quem se beneficia, quem perde? Quem paga? Quais são as consequências sociais, ambientais, pessoais etc., de seguir, ou de não seguir, um curso de ação particular? Que outros cursos de ação estão disponíveis? Essas questões não irão sempre - talvez apenas raramente - produzir concordâncias, mas enfrentá-los é sem dúvida fundamental para qualquer programa educacional 
que pretende levar a literacia tecnológica para todos ${ }^{20}$.

A internet bastante incipiente, então conhecida como Arpanet devido ao seu desenvolvimento como um projeto de pesquisa do U.S. Defense Advanced Research Projects Agency (Darpa), ainda estava a um ano de seu surgimento quando o Phi Delta Kappan publicou o seguinte apelo utópico por uma tecnoliteracia centrada no computador:

Assim como os livros libertaram estudantes sérios da tirania de métodos excessivamente simples de recitação oral, computadores também podem libertar estudantes do trabalho penoso de fazer exatamente as mesmas tarefas de maneira desajustada e inadequada às suas necessidades individuais. Como no caso de outras partes da nossa sociedade, a nossa nova e maravilhosa tecnologia existe para uso benéfico. E é problema nosso aprender como usá-la bem ${ }^{21}$.

No entanto, foi principalmente depois de A Nation at Risk ${ }^{22}$ que a literacia computacional foi popularmente citada como elemento particularmente crucial para a educação.

O relatório ressuscitou uma crítica das escolas americanas feitas durante a Guerra Fria cuja atenção (especificamente em ciência e tecnologia) não era suficientemente dada no currículo dos alunos norte-americanos para que pudessem competir no mercado global do futuro, da mesma forma como foi prevista a vinda de uma "era da informação" high tech. Ocorrido em meio ao primeiro grande boom dos computadores pessoais (PCs), a Nation at Risk recomenda principalmente a criação de uma classe semestral em ciência da computação que deve:

capacitar os formandos para: (a) compreender o computador como uma informação e como dispositivo de comunicação e computação; (b) utilizar o computador no estudo e outras matérias básicas e para fins pessoais e relacionados ao trabalho; e (c) compreender o mundo dos computadores, da eletrônica e de tecnologias relacionadas ${ }^{23}$.

Enquanto A Nation at Risk declarou que os experts eram, então, incapazes de classificar a "literacia tecnológica" de maneira inequívoca, o documento argumenta claramente que essa literacia deve ser entendida em termos mais funcionais do computador (Aronowitz; Apple) e literacia da informação (Plotnick). Tecnologias tais como o computador precisam ser vistas de acordo com um conjunto de novas habilidades, bem como o discurso profissional precisa começar a destacar o "novo vocacionalismo", em que as necessidades da indústria eram identificadas como prioridades educacionais (Grubb). Examinando esse desenvolvimento, Stephen Petrina ${ }^{24}$ conclui: "Em meados da década de 1980 nos EUA, a educação e a literacia tecnológica tinham sido definidas por meio dos interesses capitalistas de empresas privadas e do Estado". Besser ${ }^{25}$ ressalta como esse período foi fundamental na construção da educação como um mercado.

Os anos 1990 viram essa emergência e, até certo ponto, as consequências de tal raciocínio enquanto a World Wide Web vinha à tona e a florescente internet criava uma fronteira eletrônica "ponto-com" no boom econômico com a sua comercialização em uma variedade de hardwares e softwares de computação
21 SUPPES, P. Computer Technology and the Future of Education. Phi Delta Kappan. Abril 1968, p. 423.

22 NATIONAL Commission on Excellence in Education. A Nation at Risk: The Imperative for Educational Reform. Washington, DC, 1983

23 Idem, ibidem.

24 PETRINA, S., op. cit., p. 183.

25 BESSER, H. Education as Marketplace. In: Muffoletto, R.; Knupfer, N. (eds.). Computers in Education: Social, Historical, and Political Perspectives. Nova Jersey: Hampton Press, 1993. 
26 U.S. Department of Education. Getting America's Students Ready for the $21^{\text {st }}$ Century - Meeting the Technology Literacy Challenge, A Report to the Nation on Technology and Education. Nationa Education Technology Plan. Washington, D.C., 1996.

27 Idem

28 U.S. Department of Education. Toward a New Golden Age in American Education: How the internet, the Law, and Today's Students are Revolutionizing Expectations. National Education Technology Plan. Washington, D.C., 2004, p. 4.

29 A definição de "tecnocracia" é fornecida por Kovel (1983, p. 9) como sendo a ordem social em que "a lógica da máquina se instala no espírito do mestre. Há que se vestir-se 'livre de valores' sobre racionalidade técnica".

30 U.S. Congress. No Child Left Behind Act of 2001. Public Law 107-110. Washington, D.C., 2001.

31 Em 2002, a Associação Internacional de Educação Tecnológica emitiu seus Padrões para a Educação Tecnológica: conteúdo para o estudo de tecnologia, que pretende ser definitivo para o campo. Para ser justo, pelo menos oito dos seus 20 padrões evocam a possibilidade de componentes afetivos que vão além das abordagens funcionais baseadas no mercado, que narramos aqui. No entanto, como Petrina (2000, p. 186) observa, o diretor do programa Tecnologia para Todos os Americanos que estava envolvido na criação de normas declarou que elas eram "o elo vital para aumentar a competitividade global dos Estados Unidos no futuro", e assim suas preocupações profissionais e econômicas devem ser consideradas como centrais. pessoal. Na era da Microsoft e da America Online, habilidades computacionais e informativas eram de fato cada vez mais necessárias. A "estrada de dados" de Al Gore da década de 1970 desenvolveu uma ordem de magnitude até se tornar a "superestrada da informação" do mandato de Clinton; e o plano por uma "infraestrutura Global de Informação" estava sendo promovido como "uma metáfora para democracia" (Gore), e a transformação social e tecnológica despertou globalmente sob as pressões da "nova economia" (Kelly).

No final da década, a literacia tecnológica era claramente um desafio que poderia ser ignorado apenas por sua conta e risco. No entanto, de acordo com a lógica da década de 1980, como a literacia foi novamente concebida em termos muito funcionais como "significado de habilidades de usar o computador e outras tecnologias para melhorar o aprendizado, a produtividade e o desempenho" ${ }^{26}$. Mais especificamente, o Departamento definiu o desafio como um treinamento para o futuro, que deveria ter lugar nas escolas, levando, assim, uma série de questões levantadas pela revolução da informação para fora da esfera pública e reduzindo-as a competências técnicas e profissionais padronizadas para as quais crianças e jovens devem ser treinados. Além disso, a literacia tecnológica, concebida como "novas competências básicas"27 tornou-se a palavra da moda que significava um programa político para saturar as escolas com tecnologia computacional, bem como a formação para professores e alunos. Desse modo, ela não só garantia um mercado à empresas de tecnologia americanas para vender seus produtos e serviços, mas criava novas esferas para a expansão do desenvolvimento profissional, bem como responsabilizava professores e administradores por infundir corretamente a informática nos currículos.

Chega o tempo do segundo mandato do governo Bush/Cheney, o Plano Nacional de Educação Tecnológica dos EUA é citado com aprovação de um aluno de ensino médio, que comentou: "Nós temos a tecnologia em nosso sangue" ${ }^{28}$. Os efeitos de duas décadas de debate e de orientação sobre tecnoliteracia foram assim saudados tanto como um sucesso tecnocrático retumbante como uma pressão contínua sobre as instituições de ensino para inovar de acordo com os padrões da época ${ }^{29}$. É interessante notar, no entanto, que o próprio Plano afastou-se da linguagem da literacia tecnológica e voltou-se para o termo mais específico "literacia informática". Ainda assim, no seu grande gesto pelo No Child Left Behind Act de 2001 - que difundia a tecnologia com o uso de computadores multimídia e da internet nos currículos escolares de artes e ciências e fazendo com que os alunos fossem "tecnologicamente letrados ao fim da oitava série, independentemente de sua raça, etnia, sexo, renda familiar, localização geográfica ou deficiência" ${ }^{30}$, os Estados Unidos demonstraram seu compromisso permanente de delimitar o "letramento tecnológico" nos termos funcionais e economicistas das competências baseadas no computador ${ }^{31}$.

Ao encerrar nossa análise da evolução da tecnoliteracia nos Estados Unidos, devemos mencionar a forma como essas tendências políticas educacionais têm 
sido em grande parte ampliadas e aprofundadas no governo de Obama. Uma das primeiras grandes empreitadas do governo relacionadas ao setor educacional foi a realização da passagem do Ato de Recuperação e Reinvestimento Americano de 2009. Como Pierce ${ }^{32}$ discute, $3 \%$ do PIB anual foi dedicado diretamente para pesquisa científica e tecnológica, com o ensino de "Ciência, Tecnologia, Engenharia, Matemática [STEM, em inglês] sendo um dos loci mais importantes desta legislação"33. Identificando isso como parte de uma era "neoSputnik" na educação, em que as escolas estão cada vez mais sendo usadas para reproduzir e normalizar uma emergente ideologia "biocapitalista", bem como para ensinar o desenvolvimento de habilidades funcionais como uma espécie de subsídio em capital humano para a indústria biocapitalista, o trabalho de Pierce ecoa outra pesquisa educacional crítica recente (Hyslop-Margison e Naseem; Baez e Boyles) que argumenta que a tentativa da política atual de instanciar amplamente normas do tecnicismo pedagógico e cientificismo é ideologicamente desumanizante no serviço de pesquisa neoliberal capitalista e no desenvolvimento de objetivos. Assim, não é de estranhar que no último Plano Nacional de Educação Tecnológica ${ }^{34}$ os computadores, os novos meios de comunicação, a internet e outras formas de tecnologia digital foram então amplamente promovidos — não apenas por meio do currículo e enquanto currículo ${ }^{35}$, mas enquanto necessidade de avaliar a aprendizagem, para a preparação e interligação comunicativa de toda força de trabalho docente para funcionar como uma forma de autovigilância, para a reformulação tecnológica sistêmica das escolas e de outras infraestruturas de ensino, bem como para o reforço das normas de produtividade e de eficiência econômica estabelecidas como aceitáveis no trabalho educacional. Em suma, o plano de tecnologia educacional promove um apelo sistemático e arrebatador da tecnoliteracia funcional em todo o sistema educacional americano. Então, a tecnoliteracia não é mais concebida apenas como um conjunto redesenhado de competências para estudantes e para necessidades econômicas futuras. Agora ela representa na política as competências que devem ser trabalhadas pelos professores em suas avaliações, pelos administradores em sua liderança organizacional e financeira, bem como por agências de acreditação e escritórios do governo que buscam formas de responsabilização economicistas de todas essas várias entidades ligadas à educação.

Assim como foi reforçado no plano de 2010, as formas baseadas no computador e em competências relacionadas à "literacia digital" são hoje concebidas como "habilidades do século XXI" - uma noção política recentemente criada e que vem sendo implementada pela Parceria para as Competências do Século XXI ${ }^{36}$, conhecido como P2137. Curiosamente, o panorama do P21 sobre os resultados de aprendizagem organizados em torno de tais competências representa de alguma forma um momento de esperança na nossa política, pois estamos interessados em melhorar a educação, tanto de forma crítica quanto prática, com as condições sociais que ambos produzem e são, em parte, produzidos pela cultura midiática atual. Em nenhum lugar em toda a política educacional que pesquisamos será encontrada ênfase similar na
32 PIERCE, C. Education in the Age of Biocapitalism: Optimizing Educational Life for a Flat World. Nova York: Palgrave Macmillan, 2012.

33 Para reiterar, STEM continua a ser uma prioridade da Secretaria de Educação da administração de Obama, a corrida de Arne Duncan para os mecanismos de financiamento e disciplinares das melhores escolas (ver, por exemplo, Triangle Coalition, 2011; Kahn, 2012; White House, 2013). Assim, como Pierce (2013, p. 126) argumenta, grupos como as Academias Nacionais de Ciências têm respondido por retrabalhar os padrões científicos para torná-los mais tecnocientífico a fim de apoiar o desenvolvimento do capital humano para uma economia e sociedade biocapitalista.

34 U.S. Department of Education. Transforming American Education: Learning Powered by Technology. National Education Technology Plan. Washington, D.C., 2010.

35 Cada vez mais vemos - apelo para a adoção de tecnologias de mídia digital na educação por meio de uma demanda progressiva de "aprendizagem com design universal" (sobre isso, ver Rose, Meyer e Hitchcock, 2005). O chamado "design universal" entra no pensamento educacional em suas origens como um princípio arquitetônico que se esforçou para criar estruturas bastante inclusivas que seriam utilizadas por pessoas de diferentes habilidades. No entanto, ele continua a ser visto se a retórica de maximizar tecnologias educacionais baseadas em computadores promover a inclusão da aprendizagem democrática ou melhor, 
expulsar uma variada gama de possíveis experiências pedagógicas, com o único padrão legítimo de tecnoliteracia funcional e baseada no mercado, conforme descrito nesta seção.

36 PARTNERSHIP for $21^{\text {st }}$ Century Skills. P21 Framework Definitions. 2009. Disponível em: <www.p21.org/storage/ documents/P21_Framework_Definitions.pdf>.

37 A Parceria para As Competências do Século XXI (P21) foi fundada em 2002 como uma coalizão entre o governo Bush, a AOL Time Warner, a Apple Computer, Cable in Computer, Cisco Systems, Dell Computer, a Microsoft, a Associação Nacional de Educação, SAP, e os cofundadores Ken Kay e Diny Golder-Dardis. Hoje em dia, uma série de outras entidades empresariais juntaram-se para ajudar a criar o Quadro P21, incluindo a American Assoc Ford Motor Company, Dell, Intel, Verizon, Pearson, Follett, a AP, Lego, a Escola Goddard, Cengage. Destacando o vai e vem das parcerias entre público/privado que tem caracterizado a política neoliberal nas últimas décadas, o ex-diretor de educação da Apple, Karen Cator, tomou posse de uma cadeira na P21, deixando sua posição para assumir a liderança do Escritório de Tecnologia Educacional dos EUA, a fim de criar seu Plano Tecnológico da Educação Nacional de 2010. Por outro lado, o ex-chefe do Gabinete de George W. Bush, Tim Magner, passou a substituir Cator como o diretor da P21. Recentemente, Magner foi substituído por Dr. Helen Soulé, ex-chefe do projeto Cable in Classroom (fundação educacional da indústria do cabo) e, antes disso, por um gerente do necessidade de os alunos aprenderem a ser produtores de pensamento crítico sobre a mídia, a compreenderem as noções emergentes de literacia visual e multimídia como central junto à mídia impressa e a outras literacias tradicionais, bem como à necessidade dos alunos de aprender a alcançá-la num contexto fundador de literacias globais, cívicas, econômicas e ambientais. No entanto, todas essas expectativas estão incluídas como elementos centrais do quadro de competências de literacia do P21.

No entanto, uma coisa é enumerar essas literacias como metas; outra é interpretá-las literalmente em torno de linhas progressivas ou de outra forma que garanta que são bem estruturadas depois de se tornarem obrigatórias. Além disso, o vasto leque de entidades públicas e privadas por trás do movimento P21 sugere a possibilidade real de mecanismos de financiamento e de apoio político para que o quadro de literacia seja adotado, da mesma forma que já observamos que as parcerias corporativas dessa ordem devem ser consideradas dentro de uma trajetória histórica mais ampla. Assim, é completamente comum ver que a política educacional atual relacionada ao ensino de competências do século XXI está baseada em linguagem similar à da Aliança Nacional de Negócios, que declarou: "A saúde atual e futura da economia americana do século XXI depende diretamente de quão ampla e profundamente os americanos alcançaram um novo nível de literacia - a 'literacia do século XXI' —, que inclui fortes habilidades acadêmicas, de pensamento, de raciocínio, habilidades de trabalho em equipe e proficiência no uso de tecnologias" ${ }^{38}$. Por essa razão, pensadores educacionais progressistas como Mike Rose ${ }^{39}$ e Alfie Kohn ${ }^{40}$ juntaram-se ao coro de que essas competências do século XXI terão de estar alinhadas a outra grande política educacional emergente: a criação de um currículo com núcleo comum que se concentra especificamente em elevar os padrões acadêmicos. Aqui uma ampla gama de apoiadores, incluindo um grande número de ideólogos educacionais conservadores antes associados à A Nation at Risk e a políticas subsequentes do mesmo tipo (incluindo Diane Ravitch), a Federação Americana de Professores e outros que defendem um currículo tradicional de artes liberais e de ciências, recentemente voltaram suas críticas ao P21 em uma carta aberta em nome do Common Core ${ }^{41}$. Nesse sentido, esses críticos sugerem que o P21 ofereceria "competências" em vez de "conhecimento" e eles então passam a sugerir que o desafio da educação americana e da economia global é um dos "níveis crescentes de conhecimento e de profunda compreensão das forças que moldam nossas vidas e nosso futuro". Para esse fim, certamente concordamos. No entanto, achamos muito irônico que aqueles que ajudaram a definir as normas da política funcional americana sobre a tecnoliteracia buscam agora abandonar completamente a sua demanda para considerá-la um campo de meras "competências" que pode ameaçar a qualidade do currículo acadêmico. Além disso, ao defender que as artes e as ciências são qualitativamente diferentes da tecnoliteracia (ou seja, trata-se de conhecimento vs. competências), os críticos do Common Core polemizam de maneira problemática as artes liberais, porque eles as visualizam como fundamentais para garantir o lugar de liderança dos Estados Unidos na economia 
global. Ou seja, essa crítica do P21 não é baseada em uma denúncia humanista ou política do papel hegemônico da tecnologia digital na unilateralização da educação, ao torná-la potencialmente uma ferramenta a serviço do tecnocapitalismo transnacional, em vez de uma vocação moral e ação democrática. Na verdade, nem é preciso dizer que o movimento do Common Core tem seu próprio bloco de apoio de todos os tipos de grandes empresários, líderes de tecnologia como Bill Gates, bem como do governo federal. Assim, o debate recai sobre a questão de quais tecnologias são centrais, em quem mantêm a autoridade para controlar a sua utilização, e em quando eles são usados e por que são usados. Enquanto a P21 e o Common Core provavelmente representam blocos flutuantes de uma aliança de vários interesses internos para cada abordagem, a nossa análise destaca aqui que as forças sociopolíticas e econômicas dominantes interpolam-nos para servir à reprodução de uma visão de literacia comum baseada no mercado que, por sua vez, serve a reprodução e o avanço do tecnocapitalismo.

\subsection{As Nações Unidas}

À medida em que continuamos a articular as ideias, a nossa visão de tecnoliteracia rejeita o novo tecnocapitalismo, enquanto defende uma abordagem crítica, dialética e múltipla que mediaria dicotomias difíceis, por um lado, entre competências práticas e conhecimento acadêmico, e entre as necessidades individuais e a transformação social, de outro. Dessa forma, defendemos persistentemente o engajamento crítico rigoroso com uma diversidade de tecnoliteracias emergentes (inclusive de habilidades relacionadas com as novas tecnologias de aprendizagem), e, ao mesmo tempo, afirmamos a necessidade de conhecimento curricular humanístico e fortemente acadêmico (e as competências de produção de conhecimento), que podem também melhor servir à reconstrução de uma sociedade democrática crítica ${ }^{42}$. Em uma versão anterior deste ensaio, que explicou como as orientações políticas para este tipo de visão começaram a se materializar internacionalmente através do Projeto 2000+ das Nações Unidas: Literacia Científica e Tecnológica para Todos. Iniciada em 1993, a Unesco, junto com as onze principais agências internacionais, lançou o Projeto 2000+, a fim de preparar os cidadãos em todo o mundo durante a próxima década para entender, deliberar e implementar estratégias em suas vidas cotidianas relacionadas a "uma variedade de problemas sociais cotidianos sobre a população, saúde, nutrição e meio ambiente, bem como sobre o desenvolvimento sustentável a nível local, nacional e internacional"43. A missão do projeto destacou o grau em que as Nações Unidas concebiam a literacia tecnológica como uma prática social e de construção da comunidade, em vez de uma aptidão econômica individual. Além disso, em contraste com os movimentos funcionais da tecnoliteracia que têm dominado os Estados Unidos, o objetivo da "literacia científica e tecnológica" da ONU (STL) foi desenvolvido em diálogo com o conceito de desenvolvimento sustentáve ${ }^{44}$, e nesse sentido, pode ser pensado em consonância com outros movimentos cívicos democráticos do

departamento pessoal do Escritório de Tecnologia Educacional durante os anos de George W. Bush.

38 METIRI Group, The. Twenty-First Century Skills. In: Partnership with The North Central Regional Educational Laboratory. Disponível em: $<$ www.nysut.org/files/21. CENTURY.SKILLSOOO. PDF>. 2000.

39 ROSE, M. 21st Century Skills: Education's New Cliché. Truthdig. Disponível em: <www. truthdig.com/report/ item/21st_century_ skills_educations_new_cli che_20091208>. 2009.

40 KOHN, A. When ' $21^{\text {st }}$-Century Schooling' Just Isn't Good Enough: A Modest Proposal. Disponível em: <www.alfiekohn.org/ teaching/22century.htm>. 2012.

41 COMMON Core. A Challenge to the Partnership for $21^{\text {st }}$ Century Skills. Disponível em: <www.commoncore.org/ p21-challenge.php>. 2012.

42 Esse apelo pela integração dialética das artes liberais e da ciência com - avanço da tecnologia moderna foi defendido por Herbert Marcuse nos anos 1960. Sobre como a sua visão de "humanismo crítico" se relaciona à sua demanda de que a educação cria uma "nova ciência", ver Kahn (2006; 2010); e para uma abordagem da teoria crítica sobre a educação, ver Kellner (2006).

43 HOLBROOK, J., MUKHERJEE, A.; VARMA, V. S. (eds.). Scientific and Technological Literacy for All. Unesco and International Council of Associations for Science Education. Delhi, India: Center for Science Education and Communication, 2000, p. 1. 
44 UNESCO. Science and Technology Education: Philosophy of Project 2000+. The Association for Science Education. Paris: 1999.

45 ROYAL Society. The Public Understanding of Science. Londres: Royal Society, 1985.

46 POWER, C. Science and Technology Towards Informed Citizenship. Castme Journal, v. 7, n. 3, 1987, pp. 5-18.

47 BECKWITH, J. The Radical Science Movement in the United States. Monthly Review, v. 38, n. 3, jul./ago. 1993.

48 HOLBROOK, J., MUKHERJEE, A.; VARMA, V. S. (eds.)., op. cit. , p. 1.

49 LONSDALE, M.; MCCURRY, D. Literacy in the New Millennium. Adelaide, Australia: NCVER, 2004, p. 5.

50 UNESCO, op. cit.

51 RASSOOL, N. Literacy for Sustainable Development in the Age of Information. Londres: Multilingual Matters Ltd, 1999.

52 Ver: <www.unesco. org/new/en/communication-and-information/ media-development/ media-literacy>.

53 UNESCO. Overview of Information Literacy Resources Worldwide. Escrito por Forest Woody Horton, Jr. Paris: 2013.

54 UNESCO. Science, Technology, and Policy Initiative: Responding to the Needs of Africa. Paris: 2008. passado para a literacia em ciência e tecnologia, como uma "compreensão pública da ciência" 45 ,"ciência-tecnologia-sociedade" ${ }^{46}$ e movimentos da ciência radical ${ }^{47}$.

O fomento à STL pela Unesco foi realizado de diversas formas, dependendo especialmente das circunstâncias sociais e culturais ou das condições de ensino em que foi implantado ${ }^{48}$. Algumas delas têm enfatizado, sem dúvida, a necessidade de programas educacionais "cabeados" e da geração de capital humano para o desenvolvimento de indústrias da área de ciência e tecnologia nos Estados-membros das Nações Unidas. Por meio de programas como o Projeto 2000+, as Nações Unidas assumiram um compromisso não mercadológico com a literacia, concebendo-a mais como literacias múltiplas, "que são diversas, têm muitas dimensões e são aprendidas de diferentes formas" ${ }^{\text {" }}$. Assim, em vez de utilizar programas de tecnoliteracia para conectar os Estados-membros com uma economia global tecnocapitalista, a ONU promoveu uma "compreensão da natureza e da necessidade da literacia científica e tecnológica em relação à cultura e valores locais" ${ }^{50}$; só assim ela pode ser incorporada a tradições e culturas predominantes e atender às necessidades reais das pessoas ${ }^{51}$.

Enquanto vários programas das Nações Unidas continuam a defender a STL, deve-se notar que, desde o final do Projeto 2000+, dois desenvolvimentos políticos notáveis relacionadas à tecnoliteracia surgiram em contexto internacional. Por um lado, desde 2007, a Unesco tem estado ativamente envolvida no desenvolvimento da política da "literacia midiática e da informação" na educação para o empoderamento cívico através do ensino de "um conjunto combinado de competências" que abrangem conhecimentos, habilidades e atitudes pessoais e culturais ${ }^{52}$. Um levantamento dos tipos de campanhas MIL com que a Unesco se comprometeu, assim como a linguagem usada para descrevê-las, revela que muitas vezes elas vão ao encontro do trabalho anterior das Nações Unidas sobre a STL, e até mesmo espelham as metas ou abordagens de muitas organizações progressivas de literacia mediática nos Estados Unidos. Com efeito, uma comparação entre as definições do MIL e o quadro do P21 mostra um alinhamento possível que apoia ostensivamente a sua defesa crítica. No entanto, a iniciativa da ONU de defender adequadamente as múltiplas formas de literacias tecnológicas com base em seus contextos culturais para uma metodologia mais singular de ensinar as pessoas como produzir, ler e usar a informação global ${ }^{53}$ pode ser interpretada como um estreitamento problemático de sua agenda sobre a literacia. Além disso, uma segunda abordagem política desenvolvida pelas Nações Unidas nos últimos anos pode ser catalogada sob a linguagem da "Ciência, Tecnologia e Inovação" 54 (STI). Aqui, a noção de "inovação" começa a amarrar mais claramente as iniciativas internacionais de tecnoliteracia a uma ideologia de programas de investigação e de desenvolvimento capitalistas; e, de fato, por meio do STI a ONU tem desenvolvido a tecnoliteracia como uma forma de estudo de capacitação e de análise econômica de como países em desenvolvimento da África, Ásia e América Latina podem se industrializar cientificamente e tecnologicamente. Portanto, uma leitura da evolução da atual tecnoliteracia em âmbito internacional desenvolvida no trabalho das Nações Unidas revela multiplicidade de iniciativas, mas também 
crescente contestação dos programas de literacia mais justas e democráticas que eram antes oferecidos, a favor das formas mais funcionais.

\section{TECNOLITERACIA OPOSICIONAL: POR UMA LITERACIA CRÍTICA MÚLTIPLA}

O treinamento técnico e científico não precisa ser inimigo da educação humanística enquanto a ciência e a tecnologia na sociedade revolucionária estão a serviço da libertação permanente, do humanismo ${ }^{55}$.

Como vimos, a tecnoliteracia é, portanto, um lugar de luta, um terreno contestado utilizado pela esquerda, direita e pelo centro de diferentes nações para promover seus próprios interesses, e por isso os interessados em justiça social e ecológica deveriam procurar definir e instituir as suas próprias formas de oposição a servir os interesses da democratização e da justiça social. Poderes corporativos e estatais dominantes, bem como grupos conservadores e de direita, vêm fazendo uso sério das tecnologias de ponta e da educação para promover suas agendas. Nas batalhas políticas futuras, então, os educadores (juntamente com os cidadãos de todos os lugares) terão de encontrar formas de produzir e usar essas tecnologias para desenvolver uma pedagogia de oposição crítica que servirá aos interesses dos oprimidos. Portanto, além das literacias mais tradicionais, como as literacias impressas da leitura e da escrita, bem como outras novas literacias não digitais ${ }^{56}$, que devem ser pensadas como necessárias para o tipo de literacias múltiplas que são exigidas no mundo moderno, nós argumentamos que as formas de mídias robustamente mais críticas, o computador e as literacias multimídia precisam ser desenvolvidas como subconjuntos de um projeto maior de múltiplas tecnoliteracias que promovem a reconstrução emancipatória da tecnologia, da literacia e da sociedade em uma época de revolução tecnológica.

Tendo em vista os desafios da passagem da cultura do livro para as novas mídias e as redes sociais ${ }^{57}$, nós refutamos, no entanto, a ideia de que a tecnoliteracia torna obsoleta ou substitui a literacia impressa. De fato, no mundo emergente da tecnologia da informação e comunicação, a literacia tradicional assume importância crescente no mundo cibernético mediado por computador, uma vez que as pessoas precisam examinar criticamente essa grande quantidade de informação, colocando ênfase crescente no desenvolvimento de habilidades de leitura e de escrita. Teorias de analfabetismo secundário, em que os novos meios de comunicação contribuem para a perda completa ou parcial de competências de literacia impressa existentes devido à falta de prática, e demonstram que as novas tecnologias não podem ser consideradas para desenvolver a literacia impressa por conta própria (ver, por exemplo, Flusser).
55 FREIRE, P. Pedagogy of the Oppressed. Nova York: Herder \& Herder, 1972.

56 LANKSHEAR, C.; KNOBEL, M. Mapping Postmodern Literacies: A Preliminary Chart. The Journal of Literacy and Technology, v. 1, n. 1, outono, 2000. Disponível em: <www.literacyan dtechnology.org/v1n1/ lk.html>.

57 CARR, Nicholas. The Shallows. What the Internet is Doing to Our Brains. Nova York: Norton, 2011. 
comunicação \& educação • Ano XX • número 2 • jul/dez 2015

\subsection{Literacias midiáticas críticas}

Com o surgimento de uma cultura midiática global, a tecnoliteracia é sem dúvida mais importante do que nunca, uma vez que mídias são, essencialmente, tecnologias. Recentemente, os estudos culturais e a pedagogia crítica começaram a nos ensinar a reconhecer a ubiquidade da cultura midiática na sociedade contemporânea, das tendências de crescimento em relação à educação multicultural e da necessidade de uma educação para os media que aborda a questão da diferença multicultural e social ${ }^{58}$. Além disso, há um reconhecimento crescente de que as representações midiáticas ajudam a construir as nossas imagens e compreensão do mundo e que a educação deve atender o duplo desafio de ensinar a literacia mediática numa sociedade multicultural e de sensibilizar os estudantes e públicos para as desigualdades e as injustiças sociais de gênero, raça e desigualdades de classe e a discriminação. Além disso, estudos críticos têm apontado o papel da mídia no agravamento ou diminuição dessas desigualdades, bem como as formas que a educação midiática e a produção de mídias alternativas podem ajudar a criar um multiculturalismo saudável de diversidade e com democracia fortalecida. Enquanto ganhos significativos têm sido mostrados, uma mudança tecnológica contínua significa que os envolvidos na teorização e na prática da literacia mediática enfrentam algumas das mais graves dificuldades e problemas que nos são impostos como educadores e cidadãos contemporâneos, incluindo a transmissão de competências de literacia do livro e a capacidade de fazer leitura fundamentada e pensamento crítico, à luz das novas mídias e redes sociais constantemente em avanço.

Desenvolver a literacia e a pedagogia midiática crítica também envolve perceber como a mídia, tais como filmes e vídeos, podem ainda ser usados de forma positiva para ensinar uma vasta gama de assuntos, como a compreensão multicultural e a educação e a literacia ecológica. Se, por exemplo, a educação multicultural significa alcançar a diversidade genuína e expandir o currículo, é importante para os grupos excluídos do ensino regular aprenderem sobre a sua própria herança, assim como é para os grupos dominantes explorarem as experiências e as vozes da minoria e de grupos excluídos. Assim, a literacia midiática pode promover uma tecnoliteracia mais multicultural, concebida como compreensão e engajamento da heterogeneidade das culturas e subculturas que constituem um mundo cada vez mais global e multicultural ${ }^{59}$.

A literacia midiática crítica não só ensina os alunos a aprender a partir da mídia, para resistir à sua manipulação e para utilizar seus materiais de forma construtiva, mas também está preocupada com o desenvolvimento de habilidades que ajudarão a criar bons cidadãos, tornando-os mais motivados e competentemente participativos da vida social. Como Dewey ${ }^{60}$ argumenta, a educação é necessária para permitir que as pessoas participem da democracia, pois sem uma população educada, informada e letrada, a democracia forte torna-se impossível. Além disso, existem ligações cruciais entre literacia, democracia, 
empoderamento e participação social na política e na vida cotidiana. Assim, sem desenvolver literacias adequadas, a diferença entre "possuidores" e "despossuídores" não pode ser vencida, e então os indivíduos e grupos ficarão sem as ferramentas para navegar e desafiar a economia emergente global, a sociedade em rede, e a cultura midiática eletrônica.

As tecnologias de comunicação estão se tornando cada vez mais acessíveis aos jovens e a cidadãos comuns, e podem ser usadas para promover a educação, a autoexpressão democrática e o progresso social. Tecnologias que poderiam ajudar a dar fim à democracia participativa, transformando a política em espetáculos midiáticos e da guerra de imagens, tornando espectadores zumbis culturais, também poderiam ser usadas para ajudar a revigorar o debate democrático e a participação ${ }^{61}$. Na verdade, elas devem ser usadas desta última forma, pois, como Carmen Luke escreveu, "a não ser que os educadores assumam a liderança no desenvolvimento de pedagogias adequadas para estes novos meios eletrônicos e para formas de comunicação, especialistas corporativos serão os únicos a determinar como as pessoas irão aprender, o que aprenderão, e o que será literacia"62. Como vimos, esse é exatamente o perigo que está se desdobrando por meio da promoção acrítica da necessidade de ensinar "competências do século XXI" para o sucesso no mercado de trabalho global.

A literacia midiática crítica deve ser conectada com o projeto de democracia radical, uma vez que ela está preocupada em desenvolver tecnologias que irão melhorar a democratização e a participação. A esse respeito, a literacia midiática crítica toma uma abordagem abrangente que ensina atitudes críticas e proporciona a utilização experimental dos meios de comunicação como tecnologias de comunicação e de mudança social ${ }^{63}$.

\subsection{Literacias computacionais críticas}

Para participar plenamente da sociedade high tech e global, as pessoas devem cultivar novas formas de literacia computacional de formas que vão além das noções técnicas padrão. Literacia informática crítica envolve aprender a usar tecnologias computacionais para fazer pesquisa e coletar informações, para perceber a cultura do computador como um terreno contestado que contém textos, espetáculos, jogos e multimídia interativa, bem como questionamentos da economia política, preconceitos culturais e efeitos ambientais das tecnologias relacionadas ao computador ${ }^{64}$.

As ciberculturas emergentes podem ser vistas como um local discursivo e político em que os alunos, professores e cidadãos podem intervir, participando de grupos de discussão e de projetos colaborativos de pesquisa e criação de sites, produzindo multimídias inovadoras para disseminação cultural e para o cultivo de novos modos de interação social e de aprendizagem. Os computadores
61 KELLNER, D. From 9/11 to Terror War: The Dangers of the Bush Legacy. Lanham, MD: Rowman \& Littlefield.

62 Idem, p. 71.

63 HAMMER, R. Strategies for Media Literacy. In: MCLAREN, P.; HAMMER, R.; SHOLLE, D.; REILLY; S. Rethinking Media Literacy: a A critical Critical pedagogy Pedagogy of representationRepresentation. Nova York: Peter Lang, 1995, pp. 225-235.

64 PARK, L. S.; PELLOW, D. N. Racial Formation, Environmental Racism, and the Emergence of Silicon Valley. Ethnicities, v. 4, n. 3, 2004, pp. 403-424.

PLEPYS, A. The Grey Side of ICT. Environmental Impact Assessment Review, v. 22, 2002, pp. 509-523.

HEINONEN, S., JOKINEN, P.; KAIVO-OJA, J. The Ecological Transparency of the Information Society. Futures, v. 33, 2001, pp. 319-337.

BOWERS, C. A. Let Them Eat Data: How Computers Affect Education, Cultural Diversity, and the Prospects of Ecological Sustainability. Athens, GA: University of Georgia Press, 2000.

65 KAHN, R.; KELLNER, D. internet Subcultures and Oppositional Politics. In: MUGGLETON, D. (ed.). The Post-Subcultures Reader. Londres: Berg Publishers, 2003. 
podem, assim, permitir que as pessoas participem ativamente da produção da cultura, indo do diálogo e o debate sobre questões públicas para a criação e expressão de suas próprias formas culturais. Assim, os computadores e a internet podem proporcionar oportunidades para múltiplas vozes, para comunidades on-line alternativas e maior ativismo político ${ }^{65}$. No entanto, participar dessa cultura requer múltiplas formas de tecnoliteracia.

Afinal, as competências de literacia impressa - que são geralmente restritas à elite crescente de estudantes que têm o privilégio de frequentar escolas públicas e privadas adequadas e de qualidade superior — não são apenas necessárias, mas na verdade também exigem uma literacia crítica da informação. Tal literacia exigiria aprender a distinguir informações boas de ruins, identificando o que Burbules \& Callister ${ }^{66}$ conceituam como desinformação, informação errada, informação confusa e informação praticamente inútil. Nesse sentido, a literacia da informação está intimamente ligada à educação, ao aprendizado de onde a informação é encontrada, a como produzir conhecimento e compreensão e como avaliar criticamente e interpretar fontes e materiais de informação. Ela também levanta profundas questões de poder e de conhecimento relacionadas às definições de conhecimento de alto e baixo nível, quem produz e valoriza as diferentes modalidades de informação, cujas ideias são divulgadas, discutidas e marginalizados.

66 BURBULES, N.; CALLISTER, T. Watch IT: The Risks and Promises of Information Technology. Boulder: Westview Press, 2001.

67 HAMMER, R.; Kellner, D. Multimedia Pedagogy and Multicultural Education for the New Millennium. Current Issues in Education, v. 4, n. 2, 2001. Disponível em: $<$ http://cie.ed.asu.edu/ volume4/number2>.

Idem (eds.). Media/ Cultural Studies: Critical Approaches. Nova York: Peter Lang Publishing, 2009.

68 GARDNER, H. Frames of Mind. New York: Basic Books Inc, 1983.

\subsection{Literacias multimídia críticas}

Com uma cibercultura multimídia em constante desenvolvimento, além da cultura do cinema e da televisão popular, a literacia visual assume importância cada vez maior. Em seu conjunto, as telas do computador são mais gráficas, multissensoriais e interativas do que as impressões convencionais, o que desconcertou muitos de nós quando entramos em contato com os novos ambientes. Ícones, janelas, mouses e vários cliques, links e interações envolvidos no hipertexto mediado pelo computador ditam novas competências e uma dramática expansão da literacia no contexto das competências.

Visualidade é, obviamente, crucial, convencendo usuários a analisar perspicazmente campos visuais, perceber e interagir com ícones e gráficos, e utilizar dispositivos técnicos como um mouse para acessar o material e espaço desejado. Mas tato também é importante, uma vez que os indivíduos devem aprender habilidades de navegação, de como proceder a partir de um campo e de uma tela para outra, como negociar hipertextos e links, e como passar de um programa para outro quando operamos, como a maioria de nós hoje fazemos, em ambientes computacionais baseados em janelas. Além disso, como a voz e o som entram na cultura multimídia, a audição refinada também se torna parte da estética e de pedagogias de uma tecnoliteracia que deve possibilitar vários métodos de aprendizagem ${ }^{67}$.

Ambientes multimídia contemporâneos exigem uma diversidade de tipos de interações multissemióticas e multimodais, envolvendo interfaces com palavras e materiais impressos e muitas vezes imagens, gráficos, bem como materiais de áudio 
e vídeo ${ }^{68}$. Como a convergência tecnológica se desenvolve em ritmo acelerado, os indivíduos terão de combinar as habilidades de literacia midiática crítica com a literacia impressa tradicional e as novas formas de literacias múltiplas para poder acessar, navegar e participar da realidade multimediada. Leitura e interpretação de material impresso era o modo apropriado de literacia para uma época em que a principal fonte de informações eram livros e tabloides, enquanto a literacia multimídia crítica implica a leitura e a interpretação de uma infinidade de discursos, imagens, espetáculos, narrativas e de formas e gêneros de cultura midiática global. Assim, a tecnoliteracia nessa concepção envolve a capacidade de engajar efetivamente em modos de comunicação multimídia, que incluem a impressão, a fala, a visualidade, o tato e o som, dentro de um campo híbrido que combina todas essas formas, que incorporam habilidades de interpretação e crítica.

\section{RECONSTRUINDO A TECNOLITERACIA E A SOCIEDADE}

Nós somos, com certeza, designers de nossos recursos sociais ${ }^{69}$.

Enfrentar adequadamente o desafio criado pelo conceito de tecnoliteracia levanta questões sobre a concepção e a reconstrução da própria tecnologia. Como Andrew Feenberg argumentou há muito tempo ${ }^{70}$, a democratização da tecnologia muitas vezes requer a sua reconstrução e revisão por indivíduos. Hackers redesenham sistemas tecnológicos, a partir principalmente de movimentos anticapitalistas de open source e de software livre, e na verdade grande parte da internet em si tem sido o resultado de indivíduos construindo conhecimento coletivamente e fazendo melhorias que ajudam vários projetos educacionais, políticos e culturais. É claro, existem restrições corporativas e técnicas em que programas dominantes e máquinas impõem suas regras e habilidades sobre os usuários, mas parte da tecnoliteracia revisada requer a própria percepção e transformação de seus limites. A tecnoliteracia deve ajudar a ensinar as pessoas a se tornar produtores mais éticos, bem como os consumidores, e, assim, ela poderá ajudar a redesenhar e a reconstruir a tecnologia moderna para torná-la mais aplicável às necessidades das pessoas, e não apenas aos seus desejos manufaturados.

Certamente, as tecnoliteracias alternativas devem se tornar reflexivas e críticas, conscientes dos pressupostos educativos, sociais e políticos envolvidos na reestruturação da educação, da tecnologia e da sociedade contemporânea. Em resposta ao hype excessivo, relativo às novas tecnologias e educação, é importante manter a dimensão crítica e refletir sobre a natureza e os efeitos das tecnologias emergentes e das pedagogias desenvolvidas como uma resposta ao seu desafio. Muitos defensores das novas tecnologias, no entanto, abstêm-se de crítica a favor de uma agenda mais afirmativa.

Por exemplo, depois de uma excelente discussão sobre os novos modos de literacia e sobre a necessidade de repensar a educação, Gunther Kress ${ }^{71}$
69 NEW London Group. A Pedagogy of Multiliteracies: Designing Social Futures. Harvard Educational Review, v. 66, 1996, pp. 60-92.

70 FEENBERG, A. Critical Theory of Technology. Nova York: Oxford University Press, 1991.

Alternative Modernity. Berkeley: University of California Press, 1995.

Questioning Technology. Nova York/Londres: Routledge, 1999.

71 KRESS, G. Visual and Verbal Modes of Representation in Electronically Mediated Communication: The Potentials of New Forms of Text. In: Snyder, I. (ed.). Page to Screen: Taking Literacy into the Electronic Era. Sydney, Australia: Allen \& Unwin, 1997, pp. 53-79. 
argumenta que devemos passar da crítica ao projeto, de uma desconstrução negativa a uma construção mais positiva. Mas em vez de seguir essa lógica moderna de ou isso/ou aquilo, pedagogos críticos deverão prosseguir a lógica de ambos/e, percebendo criação e crítica, desconstrução e reconstrução como opções complementares e suplementares, e não como antitéticas. Certamente, precisamos projetar pedagogias alternativas e currículos para o futuro, bem como o desenvolvimento de melhores relações sociais e culturais, mas precisamos também criticar o mau uso, o uso inadequado, reivindicações exageradas, exclusões e opressões envolvidos na introdução das TIC na educação. Além disso, a dimensão crítica é mais do que nunca necessária enquanto tentarmos desenvolver abordagens contemporâneas da tecnoliteracia e design mais emancipatórias e democratizadoras das tecnologias. Nesse processo, devemos ser vigilantes críticos, praticando a crítica e a autocrítica, pondo em causa os nossos pressupostos, discursos e práticas, à medida que procuramos desenvolver tecnoliteracias e pedagogias de resistência ${ }^{72}$.

Com a Primavera Árabe em 2011 na Tunísia, Egito e Líbia, vemos que as insurgências políticas e revoluções foram se desdobrando como espetáculos midiáticos que circularam imagens e discursos de revolta, liberdade e democracia por meio da mídia global, bem como pelas mídias sociais locais. Essas insurreições - que eclodiram no final de janeiro de 2011 e continuaram a abalar o mundo e a reconstituir a paisagem política do Norte da África e no Oriente Médio durante a Primavera, ao longo de 2011 e no futuro - podem ser vistas em retrospectiva inaugurando uma nova época da história, em que levantes políticos e insurreições radicalizaram regiões inteiras do mundo e expulsaram ditaduras corruptas e arraigadas. Além disso, com a ascensão de movimentos de ocupação que foram de Wall Street para a Main Street nos Estados Unidos, bem como movimento de oposição em erupção na Europa em resposta à crise fiscal do estado capitalista, 2011 pode aparecer como o novo 1968, como um mercado de luta global radical e insurreição ${ }^{73}$.

Para nossos propósitos, é significativo que os agentes das insurreições do Norte da África até Nova York e Atenas estavam usando as novas mídias e as redes sociais para promover a revolta e lutar pela democracia, liberdade e justiça social. Os agentes da luta muitas vezes eram jovens usando suas habilidades com novas mídias e redes sociais para promover a luta, demonstrando como as tecnoliteracias críticas podem transformar teoria em prática e como a nova mídia e as redes sociais podem se tornar instrumentos de mudança social.

72 KELLNER, D. Media Spectacle. Londres/Nova York: Routledge, 2003a.

73 Idem. Media Spectacle and Insurrection, 2011: From the Arab Uprisings to Occupy Everywhere! Londres/Nova York: Continuum/Bloomsbury, 2012.
Resumindo, as pessoas devem ser ajudadas a desenvolver as múltiplas tecnoliteracias que lhes permitam compreender, criticar e transformar as condições sociais e culturais opressivas em que vivem, ao mesmo tempo em que se tornam ecologicamente informadas, éticas e sujeitos transformadores em oposição a objetos de dominação e manipulação tecnológica. Isso requer a produção de literacias de oposição múltiplas para a geração de pensamento crítico, reflexão e capacidade de se engajar na elaboração de discursos, artefatos culturais, 
mobilização social e ação política em meio a revolução tecnológica generalizada, crises econômicas e políticas globais e uma nova era de insurreição. Além disso, como sujeitos ativos e engajados surgem por meio das interações sociais com outras pessoas, uma noção de tecnologias de convívio deve vir a ser uma parte dos tipos de tecnoliteracia que uma reconstrução radical da educação quer cultivar.

Certamente, o projeto de reconstrução da tecnoliteracia deve assumir diferentes formas em diferentes contextos para abrir novas possibilidades para a transformação social progressista. Em quase todas as situações culturais e sociais, no entanto, a literacia crítica deve ser aprimorada para que os cidadãos possam nomear o sistema tecnológico, descrever e compreender as mudanças tecnológicas em curso e que definem e caracterizam uma nova ordem global, bem como aprender a se envolver experimentalmente em críticas e práticas de oposição, a favor da democratização, da justiça social e do bem-estar ecológico. Como parte de uma ordem verdadeiramente multicultural, temos de incentivar o crescimento e a prosperidade das inúmeras posições ${ }^{74}$ sobre a tecnoliteracia, olhando para fora para legitimar necessidades, valores e entendimentos contra-hegemônicos. Isso equivaleria a reconhecer e promover várias tecnoliteracias "de baixo", em oposição à tecnoliteracia "de cima", predominantemente funcional, economicista e tecnocrática favorecida por muitos setores e estados. Desse modo, os projetos de tecnoliteracia podem permitir oportunidades de reconstrução de um mundo melhor que será forjado fora da contemporaneidade cheia de crises, insurreições e lutas sociais.

\section{REFERÊNCIAS}

APPLE, M. Is New Technology Part of the Solution or Part of the Problem in Education. In: Beynon, J.; Mackay, H. (ed.). Technological Literacy and the Curriculum. Londres: The Falmer Press, 1992.

ARONOWITZ, S. Why Should Johnny Read? The Village Voice Literary Supplement, maio 1995.

BAEZ, B.; BOYLES, D. The Politics of Inquiry: Education Research and the “Culture of Science”. Albany, NY: State University of New York Press, 2009.

BECKWITH, J. The Radical Science Movement in the United States. Monthly Review, v. 38, n. 3, jul./ago. 1993.

BESSER, H. Education as Marketplace. In: Muffoletto, R.; Knupfer, N. (eds.). Computers in Education: Social, Historical, and Political Perspectives. Nova Jersey: Hampton Press, 1993.

BEST, S., and Kellner, D. The Postmodern Adventure: Science, Technology, and Cultural Studies at the Third Millennium. Nova York/Londres: Guilford Press and Routledge, 2001.

74 HARDING, S. (ed.). The Feminist Standpoint Theory Reader: Intellectual and Political Controversies. Nova York/Londres: Routledge, 2004. 
BOWERS, C. A. Let Them Eat Data: How Computers Affect Education, Cultural Diversity, and the Prospects of Ecological Sustainability. Athens, GA: University of Georgia Press, 2000.

BRUNDTLAND, G. H. et al. Our Common Future: Report of the World Commission on Environment and Development. Oxford: Oxford University Press, 1987.

BURBULES, N.; CALLISTER, T. Knowledge at the Crossroads. Educational Theory, v. 46, n. 1, 1996, pp. 23-34.

. Watch IT: The Risks and Promises of Information Technology. Boulder: Westview Press, 2001.

BROMLEY, H.; APPLE, M. (eds.). Education/ Technology/Power: Educational Computing as Social Practice. Albany, NY: State University of New York Press, 1998.

CARR, Nicholas. The Shallows. What the Internet is Doing to Our Brains. Nova York: Norton, 2011.

CASTELLS, M. The Information Age: Economy, Society and Culture Vol.I: The Rise of the Network Society. Cambridge: Blackwell Publishers, 1996.

COMMON Core. A Challenge to the Partnership for $21^{\text {st }}$ Century Skills. Disponível em: <www.commoncore.org/p21-challenge.php>. 2012.

COPE, B.; KALANTZIS, M. (eds.). Multiliteracies: Literacy learning and the design of social futures. Nova York: Routledge, 2000.

COPPOLA, N. W. Greening the Technological Curriculum: A Model for Environmental Literacy. Journal of Technology Studies, v. 25, n. 2, 1999, pp. 39-46.

COURTS, P. L. Multicultural Literacies: Dialect, Discourses, and Diversity. Nova York: Peter Lang, 1998.

DEWEY, J. Democracy and Education: An Introduction to the Philosophy of Education. Carbondale and Edwardsville: Southern Illinois University Press, 1916.

DYRENFURTH, M. J. Technological literacy synthesized. In: DYRENFURTH, M. J.; KOZAK, M. R. (eds.). 1991.

_. Technological literacy. Peoria, IL: Glencoe, McGraw-Hill.

FEENBERG, A. Critical Theory of Technology. Nova York: Oxford University Press, 1991.

Alternative Modernity. Berkeley: University of California Press, 1995.

Questioning Technology. Nova York/Londres: Routledge, 1999. 
FLUSSER, V. Does Writing Have a Future? Trad. N. A. Roth. Minneapolis: University of Minnesota Press, 2011.

FREIRE, P. Pedagogy of the Oppressed. Nova York: Herder \& Herder, 1972.

FREIRE, P.; MACEDO, D. Literacy: Reading the Word and the World. Westport, CT: Bergin \& Garvey, 1987.

GARDNER, H. Frames of Mind. Nova York: Basic Books Inc, 1983.

GORE, A. Remarks Prepared for Delivery. Discurso proferido na International Telecommunications Union. Buenos Aires: 1994. Disponível em: <http:/ /263. aka.org.cn/Magazine/Aka4/gorestalk.html>.

GROSSMAN, E. High-tech Wasteland. Orion, jul./aug. 2004. Disponível em: <www.oriononline.org/ pages/om/04-4om/Grossman.html>.

GRUBB, W. N. The New Vocationalism - What It Is, What It Could Be. Phi Delta Kappan, v. 77, n. 8, 1996, pp. 535-546.

HAMMER, R. Strategies for Media Literacy. In: MCLAREN, P.; HAMMER, R.; SHOLLE, D.; REILLY; S. Rethinking Media Literacy: a A Critical Pedagogy of Representation. Nova York: Peter Lang, 1995, pp. 225-235.

HAMMER, R.; KELLNER, D. Multimedia Pedagogy and Multicultural Education for the New Millennium. Current Issues in Education, v. 4, n. 2, 2001. Disponível em: <http:/ / cie.ed.asu.edu/volume4/number2>. . (eds.) Media/Cultural Studies: Critical Approaches. Nova York: Peter Lang Publishing, 2009.

HARDING, S. (ed.). The Feminist Standpoint Theory Reader: Intellectual and Political Controversies. Nova York/Londres: Routledge, 2004.

HAYDEN, M. What is technological literacy? Bulletin of Science, Technology and Society, v. 119, STS Press, 1989, pp. 220-233.

HEINONEN, S., JOKINEN, P.; KAIVO-OJA, J. The Ecological Transparency of the Information Society. Futures, v. 33, 2001, pp. 319-337.

HICKMAN, L. Philosophical Tools for Technological Culture. Bloomington: Indiana University Press, 2001.

HOLBROOK, J., MUKHERJEE, A.; VARMA, V. S. (eds.). Scientific and Technological Literacy for All. Unesco and International Council of Associations for Science Education. Delhi, India: Center for Science Education and Communication, 2000.

HYSLOP-MARGISON, E. J. \& M. A. Naseem. Scientism and Education: Empirical Research as Neo-Liberal Ideology. Nova York: Springer, 2007.

ILLICH, I. Tools for Conviviality. Nova York: Harper and Row, 1973. 
JENKINS, E. W. Technological Literacy: Concepts and Constructs. Journal of Technology Studies, v. 23, n. 1, 1997.

KAHN, R. The Educative Potential of Ecological Militancy in an Age of Big Oil: Towards a Marcusian Ecopedagogy. Policy Futures in Education, v. 4, n. 1, 2006, pp. 31-44.

.Critical Pedagogy Taking the Illich Turn. The International Journal of Illich Studies, v. 1, n. 1, 2004. Disponível em: <http://ivan-illich.org/ wp-content/uploads/2013/02/7-30-3-PB.pdf>.

. Critical Pedagogy, Ecoliteracy, and Planetary Crisis: The Ecopedagogy Movement. Nova York: Peter Lang Publishing, 2010.

. Afterword. In: EVANS, T. L. Occupy Education: Living and Learning Sustainability. Nova York: Peter Lang, 2012.

KAHN, R.; KELLNER, D. Internet Subcultures and Oppositional Politics. In: MUGgletON, D. (eds.). The Post-Subcultures Reader. Londres: Berg Publishers, 2003.

Oppositional Politics and the Internet: A Critical/Reconstructive Approach. Cultural Politics, v. 1, n. 1, Berg Publishers, 2005.

. Paulo Freire and Ivan Illich: Technology, Politics, and the Reconstruction of Education. In: Torres, C.; Noguera, P. (eds.). Paulo Freire and the Possible Dream. Rotterdam, The Netherlands: Sense Publishers, 2007.

KELLY, K. New Rules for the New Economy. Londres, Fourth Estate: 1998.

KELLNER, D. Critical Theory, Marxism and Modernity. Baltimore, MD: Johns Hopkins University Press, 1989.

Media Culture: Identity and Politics Between the Modern and the Postmodern. Nova York, NY: Routledge, 1995.

- Multiple Literacies and Critical Pedagogy in a Multicultural Society. Educational Theory, n. 48, 1998, pp. 103-122.

. Globalization and New Social Movements: Lessons for Critical Theory and Pedagogy. In: Burbules, N.; Torres, C. A. (eds.), Globalization and Education: Critical Perspectives. Nova York: Routledge, 2000.

. Theorizing Globalization. Sociological Theory, v. 20, n. 3, nov. 2002, pp. 285-305.

. Media Spectacle. Londres/Nova York: Routledge, 2003a.

. From 9/11 to Terror War: The Dangers of the Bush Legacy. Lanham, MD: Rowman \& Littlefield. 
Toward a Critical Theory of Education. Democracy \& Nature, v. 9, n. 1. Taylor and Francis, 2003c, pp. 51-64.

. Technological Transformation, Multiple Literacies, and the Re-visioning of Education. E-Learning, v. 1, n. 1, 2004.

Media Spectacle and the Crisis of Democracy: Terrorism, War, and Election Battles. Boulder, CO: Paradigm Publishers, 2005.

Toward a Critical Theory of Education. Critical Theory and Critical Pedagogy Today. Toward a New Critical Language in Education. Ed. Ilan GurZe'ev. University of Haifa: Studies in Education, 2006, pp. 49-69.

Media Spectacle and Insurrection, 2011: From the Arab Uprisings to Occupy Everywhere! Londres/Nova York: Continuum/Bloomsbury, 2012.

KOHN, A. When “21 $1^{\text {st }}$ Century Schooling” Just Isn't Good Enough: A Modest Proposal. Disponível em: <www.alfiekohn.org/teaching/22century.htm>. 2012.

KOVEL, J. Theses on Technocracy. Telos, n. 54, inverno 1983.

KRESS, G. Visual and Verbal Modes of Representation in Electronically Mediated Communication: The Potentials of New Forms of Text. In: Snyder, I. (ed.). Page to Screen: Taking Literacy into the Electronic Era. Sydney, Australia: Allen \& Unwin, 1997, pp. 53-79.

LANKSHEAR, C.; KNOBEL, M. Mapping Postmodern Literacies: A Preliminary Chart. The Journal of Literacy and Technology, v. 1, n. 1, outono, 2000. Disponível em: <www.literacyandtechnology.org/v1nl/lk.html>.

LANKSHEAR, C.; SNYDER, I. Teachers and Technoliteracy: Managing Literacy, Technology and Learning in Schools. Sydney, Australia: Allen \& Unwin, 2000.

LEWIS, T.; GAGEL, C. Technological literacy: A critical analysis. Journal of Curriculum Studies, v. 24, n. 2, 1992.

LONSDALE, M.; MCCURRY, D. Literacy in the New Millennium. Adelaide, Australia: NCVER, 2004.

LUKE, C. Technological Literacy. Melbourne: National Languages \& Literacy Institute. Adult Literacy Network, 1997.

- Cyber-schooling and Technological Change: Multiliteracies for New Times. In: COPE, B.; KALANTZIS, M. (eds.). Multiliteracies: Literacy, Learning, and the Design of Social Futures. Australia: Macmillan, 2000.

LUKE, A.; LUKE, C. Adolescence Lost/Childhood Regained: On Early Intervention and the Emergence of the Techno-Subject. Journal of Early Childhood Literacy, v. 1, n. 1, 2001, pp. 91-120. 
comunicação \& educação • Ano XX • número 2 • jul/dez 2015

MARCUSE, H. Repressive Tolerance. In: Wolff, R. P.; Moore, Jr., B.; Marcuse, H. (eds.). A Gritique of Pure Tolerance. Boston: Beacon Press, 1965.

MCLAREN, P.; HAMMER, R.; SHOLLE, D.; REILLY, S. Rethinking Media Literacy: A Critical Pedagogy of Representation. Nova York: Peter Lang, 1995.

MCLUHAN, M. Understanding Media: The Extensions of Man. Nova York: Signet Books, 1964.

METIRI Group, The. Twenty-First Century Skills. In: Partnership with The North Central Regional Educational Laboratory. Disponível em: <www.nysut. org/files/21.CENTURY.SKILLS000.PDF>. 2000.

NATIONAL Commission on Excellence in Education. A Nation at Risk: The Imperative for Educational Reform. Washington, DC, 1983.

NATIONAL Telecommunications \& Information Administration. A Nation Online: How Americans are Expanding Their Use of the Internet. Disponível em: <www.ntia.doc.gov/ntiahome/dn/nationonline_020502.htm.> 2002.

NEW London Group. A Pedagogy of Multiliteracies: Designing Social Futures. Harvard Educational Review, v. 66, 1996, pp. 60-92.

PARTNERSHIP for 21 ${ }^{\text {st }}$ Century Skills. P21 Framework Definitions. 2009. Disponível em: <www.p21.org/storage/documents/P21_Framework_Definitions.pdf >.

PARK, L. S.; PELLOW, D. N. Racial Formation, Environmental Racism, and the Emergence of Silicon Valley. Ethnicities, v. 4, n. 3, 2004, pp. 403-424.

PEARSON, G.; Young, A. T. Technically Speaking: Why All Americans Need to Know More About Technology. National Academies Press, 2002.

PETRINA, S. The Politics of Technological Literacy. International Journal of Technology and Design Education, v. 10, n. 2, 2000.

PIERCE, C. Education in the Age of Biocapitalism: Optimizing Educational Life for a Flat World. Nova York: Palgrave Macmillan, 2012.

PLEPYS, A. The Grey Side of ICT. Environmental Impact Assessment Review, v. 22, 2002, pp. 509-523.

PLOTNICK, E. Information literacy. ERIC Clearinghouse on Information and Technology, Syracuse University, 1999. ED-427777.

POSTMAN, N. Amusing Ourselves to Death. Nova York: Viking-Penguin, 1985.

Technopolis: The Surrender of Culture to Technology. Nova York: Random House, 1992.

POWER, C. Science and Technology Towards Informed Citizenship. Castme Journal, v. 7, n. 3, 1987, pp. 5-18. 
RASSOOL, N. Literacy for Sustainable Development in the Age of Information. Londres: Multilingual Matters Ltd, 1999.

ROSE, D. H.; MEYER, A.; HITCHCOCK, C. The Universally Designed Classroom: Accessible Curriculum and Digital Technologies. Cambridge, MA: Harvard Education Press, 2005.

ROSE, M. 21st Century Skills: Education's New Cliché. Truthdig. Disponível em: <www.truthdig.com/report/item/21st_century_skills_educations_new_ cliche_20091208>. 2009.

ROYAL Society. The Public Understanding of Science. Londres: Royal Society, 1985.

SELFE, C. L. Technology and Literacy in the Twenty-First Century: The Importance of Paying Attention. Carbondale, IL: Southern Illinois University Press, 1999.

SHARE, J. Media Literacy is Elemental: Teaching Youth to Critically Read and Create Media. Nova York: Peter Lang, 2008.

STREET, B. Literacy in Theory and Practice. Cambridge, UK: Cambridge University Press, 1984.

SUPPES, P. Computer Technology and the Future of Education. Phi Delta Kappan. Abril, 1968, pp. 420-23.

TODD, R. D. The Natures and Challenges of Technological Literacy. In: DYRENFURTH, M. J.; KOZAK, M. R. (ed.). Technological Literacy. Peoria, IL: Glencoe, McGraw-Hill, 1991.

TREND, D. Welcome to Cyberschool: Education at the Crossroads in the Information Age. Lanham, Md: Rowman \& Littlefield, 2001.

TRIANGLE Coalition for Science and Technology Education. Race to the Top Round Three Requires STEM Emphasis. 2011. Disponível em: <www. trianglecoalition.org/race-to-the-top-round-three-requires-stem-emphasis $>$.

UNESCO. The Project 2000+ declaration: The way forward. Paris: 1994.

—. Science and Technology Education: Philosophy of Project 2000+. The Association for Science Education. Paris: 1999.

- Science, Technology, and Policy Initiative: Responding to the Needs of Africa. Paris: 2008.

- Overview of Information Literacy Resources Worldwide. Escrito por Forest Woody Horton, Jr. Paris: 2013.

U.S. Congress. No Child Left Behind Act of 2001. Public Law 107-110. Washington, D.C., 2001. 
U.S. Department of Education. Getting America's Students Ready for the $21^{\text {st }}$ Century - Meeting the Technology Literacy Challenge, A Report to the Nation on Technology and Education. National Education Technology Plan. Washington, D.C., 1996.

Toward a New Golden Age in American Education: How the internet, the Law, and Today's Students are Revolutionizing Expectations. National Education Technology Plan. Washington, D.C., 2004

—. Transforming American Education: Learning Powered by Technology. National Education Technology Plan. Washington, D.C., 2010.

WAETJEN, W. Technological Literacy Reconsidered. Journal of Technology Education, v. 4, n 2, 1993.

WAJCMAN, J. Technofeminism. Malden, MA: Polity Press, 2004.

WEIL, D. K. Toward a Critical Multicultural Literacy. Nova York: Peter Lang, 1998.

WELLS, H. G. World Brain. Nova York: Doubleday, 1938.

WHITE House, The. Educate to Innovate. 2013. Disponível em: <www. whitehouse.gov/issues/education/k-12/educate-innovate>.

WILSON, J. Three Key Players for $21^{\text {st }}$ Century Skills, John Wilson Unleashed. 2012. Disponível em: <http://blogs.edweek.org/edweek/john_wilson_ unleashed/2012/04/three_key_players_for_21st_century_skills.html>. 